\title{
Research
}

\section{Voluntary Participation in Regional Fisheries Management Council Meetings}

\author{
$\underline{\text { Danielle T. Brzezinski }}^{1}$, James Wilson $^{1}$, and $\underline{\text { Yong Chen }}^{1}$
}

\begin{abstract}
Insufficient and unrepresentative participation in voluntary public hearings and policy discussions has been problematic since Aristotle's time. In fisheries, research has shown that involvement is dominated by financially resourceful and extreme-opinion stakeholders and tends to advantage groups that have a lower cost of attendance. Stakeholders may exhibit only one or all of these traits but can be still similarly advantaged. The opposites of these traits tend to characterize the disadvantaged, such as the middle-ground opinions, the less wealthy or organized, and the more remote stakeholders. Remoteness or distance is the most straightforward and objective of these characteristics to measure. We analyzed the New England Fishery Management Council's sign-in sheets for 2003-2006, estimating participants' travel distance and associations with the groundfish, scallop, and herring industries. We also evaluated the representativeness of participation by comparing attendance to landings and permit distributions. The distance analysis showed a significant correlation between attendance levels and costs via travel distance. These results suggest a potential bias toward those stakeholders residing closer to meeting locations, possibly disadvantaging parties who are further and must incur higher costs. However, few significant differences were found between the actual fishing industry and attendee distributions, suggesting that the geographical distribution of the meeting attendees is statistically similar to that of the larger fishery. The interpretation of these results must take into consideration the limited time span of the analysis, as policy changes may have altered the industry make-up and location prior to our study. Furthermore, the limited geographical input of stakeholders may lend bias to the Council's perception of ecological and social conditions throughout the spatial range of the fishery. These factors should be further considered in the policy-formation process in order to incorporate a broader range of stakeholder input.
\end{abstract}

Key Words: fisheries policy; New England; voluntary participation

\section{INTRODUCTION}

The Magnuson-Stevens Fishery Conservation and Management Act (1976) established eight regional fishery management councils to oversee and regulate the United States' fisheries from 3-200 nautical miles. These councils in turn create committees that advise the Council during formation of Fishery Management Plans (FMPs). In this development process, participation of the public and stakeholders is not only encouraged, but legally mandated by the National Environmental Policy Act (NEPA) requirements, which enable development of multiple policy options to address stakeholders' concerns and to identify the option that is most suitable for achieving fishery management goals (Fishery Conservation 2005). Public participation is a legal requirement (Magnuson-Stevens 1976) and also considered a necessity for successful adaptive management in order to respond to and reflect the fishery (McCool and Guthrie 2001).

Olson (1965) suggests that as the personal stake of members in a particular group, like an industry, increases, the selective incentives of these members to affect the regulatory outcomes, perhaps through organization, also increase. Additionally, the benefits from affecting regulatory outcomes tend to increase. This type of organization is expensive, thus only those with high stakes in the policy outcome and likely to derive a net benefit participate 
(Noll 1999). These benefits can mitigate to some extent the free-rider problem that is present in voluntary participation, where private costs work against action for the public good (Olson 1965). Participation carries the primary benefit of having a role in the decision-making process, whether through a direct vote or influence on those who vote, with anticipation of a larger profit or share during the allocation process (Bulkley et al. 2001).

We feel, however, that the makeup of the voluntary participant pool has not been fully considered in the development of the participation requirement, as studies regarding participation argue that the wealthy, the geographically local, the small, and the strong-opinioned are more likely to attend and participate (Osborne et al. 2000). Specifically, Turner and Weninger (2005) observed that voluntary participants were more often groups with extreme, rather than moderate, positions. The regulated industry, the greatest component of those strong-opinion participants, is most likely to become well organized to influence regulation so as to obtain more advantageous regulation (Noll 1999). Through the feedback loop of regulation decisions and influence comes the possibility of regulatory capture by the industry, a desired goal and motivation for participation (Stigler 1971). This outcome has been noted within the regional councils (Merrell Katsouros 2003). An independent review stated that many of the council members have "an economic interest in the outcome of their votes" or at the very least have strong ties to the industry (Merrell Katsouros 2003). In this situation, these connections lead to an elevated level of influence by the industry.

Osborne et al. (2000) along with others have developed models to predict outcomes and involvement in such situations. Three features tend to be standard: nonparticipation of moderates, overall low participation, and the outcome's dependency on the attendee makeup. As noted by Turner and Weninger (2005) in their study of the mid-Atlantic surf clam and ocean quahog fishery, the opinions most often shared at public comment meetings are those of groups with extreme views. Travel to and from and time spent at these meetings is not reimbursed. These costs are borne individually by the participants, decreasing overall attendance and concentrating only those with the means or the incentives to attend. This conglomeration of the extremes produces a highly polarized setting for policy making. Participation by either extreme can flipflop a policy over separate meetings (Allen 1991, New England Fishery Management Council 1985). These observed and modeled features of participants can stem from the costs of participating (Osborne et al. 2000).

Benefits and costs to individuals or groups depend on travel costs, perceived possible influence on the outcome, and personal stake in the matter at hand. Osborne et al. (2000) pointed out that participation by individual fishermen and representative fishing groups are prime examples of costly participation having a significant effect on involvement and subsequent regulation. They noted that these individuals often travel long distances to participate in these meetings, incurring travel costs and possibly lost profits from choosing not to fish. They also indicated that regulation depends in part on the positions taken by attendees at these meetings. Becker (1983, 1985) found that regulators responded to pressure from various modeled pressure groups in terms of subsidies received and taxes paid due to public policy. They found that these groups competed to influence policy outcomes. Although these groups had no actual vote, whether as members of the public or as legislators, the pressure generated influenced the outcome of policy. Thus, regulation in these instances favored groups better able to apply pressure. For fishermen, one source of pressure involves meeting participation, whether personally or through representatives.

Previous studies have looked at the possible components and motivations for participation, although the literature has rarely focused directly on regional fisheries management. Further incentive to address this aspect of fisheries management lies in the potential ecological effects. In a heterogeneous fishery that spans a wide range of space and habitat and physical and biological conditions, a more homogeneous, localized stakeholder input may potentially bias the policy process. Thus, these concerns extend beyond the social and economic impacts of policy to the ecological interactions with the resource.

The objective of this study is to evaluate the potential bias in stakeholder participation that arises due to the costs of participating in fisheries management meetings. We want to (1) analyze attendance records for correlations between costs 
(measured as distance traveled) of attending and rates of attending; (2) analyze meeting records to determine whether voluntary, non-voting participants have influence on voted policies; and (3) evaluate whether the levels of participation are representative of the larger industry.

\section{METHODS}

\section{Study site}

This study examines participation in the New England Fishery Management Council (NEFMC), which regulates the marine fisheries in the federal waters off the New England coast. The Council meets generally five to nine times a year throughout the New England area. The NEFMC was chosen for this study because of recently expressed concerns from remotely located fishermen regarding the distance to such meetings and their continued inability to contribute input to regulations (J. Wilson, University of Maine - Orono, personal communication). Furthermore, the NEFMC had been the recipient of intense scrutiny because of the highly publicizied court case, "Conservation Law Foundation v Evans" (2001), in which the Conservation Law Foundation (CLF) sued, alleging that the National Marine Fisheries Service (NMFS) failed to prevent overfishing and minimize bycatch, thus violating the 1996 Sustainable Fisheries Act. This recent case, among others, emphasized the issues that the regional councils had with implementing the new mandates. The prominence of these cases brought increased criticism to the NEFMC and highlighted the contentious management setting.

\section{The focus fisheries}

The NEFMC manages nine fishery management plans (FMPs), encompassing a total of 28 species. This research focuses on three fisheries: the multispecies (groundfish), the Atlantic herring, and the Atlantic sea scallop fisheries. The scallop industry was the most valuable industry in New England and the mid-Atlantic in 2000 and continues to rise (Ocean Studies Board 2002). Its continued success has been attributed to the closed areas and its rotating management system, implemented by the NEFMC (Hart and Rago 2006). The groundfish fishery had a recent amendment to its FMP in 2003 that was a direct result of the CLF v Evans (2001) decision. Finally, the herring fishery was identified because of its importance as bait in the $\$ 400$ milliona-year lobster industry (NMFS 2007). These three fisheries are of particular importance to the New England area. They have been the main sources of income for fishers, as well as sources of conflict over policy decisions. Due to their regional importance, they were deemed good selections for a more focused interest study.

\section{Participation}

Public participation at the NEFMC meetings is recorded on sign-in sheets, which are available at every meeting. Individuals attending are encouraged to fill out whatever identifying information they wish, ranging from a simple self-description of status (e.g., recreational fisherman) to a full address and identification of their affiliation. These sign-in sheets are a convenient method for assessing an individual's travel costs to the meeting, using distance as a proxy, and fishery affiliations.

We gathered the sign-in sheets for the general NEFMC council meetings for the years 2003 to 2006. There were a total of 26 meetings, covering 68 days. We categorized these data according to meeting date and location, and hailing location of the participant. The hailing location of each participant was determined using the sign-in information, personal contacts, and the internet search engine Google ${ }$. The US Census provided the county subdivision levels for organizing the locations. We used ArcGIS® 9.2 (Environmental Systems Research Institute (ESRI) 2007) to project the data points and calculate the as-the-crow-fliesdistance from each hailing point to the meeting location point. ArcGIS also calculated the meeting locations' mean center.

To the extent possible, we identified each participant's affiliations with the herring, scallop, or groundfish fisheries using associated data such as fishing permits, cooperative affiliations, and employment. Each identified individual was assigned to one of the three target fisheries. For some individuals, this affiliation changed for different meetings and was adjusted to reflect the signed-in affiliation. An average percentage of industry participation per meeting date provided a 
Fig. 1. Mean center for 2003-2006 NEFMC meetings.

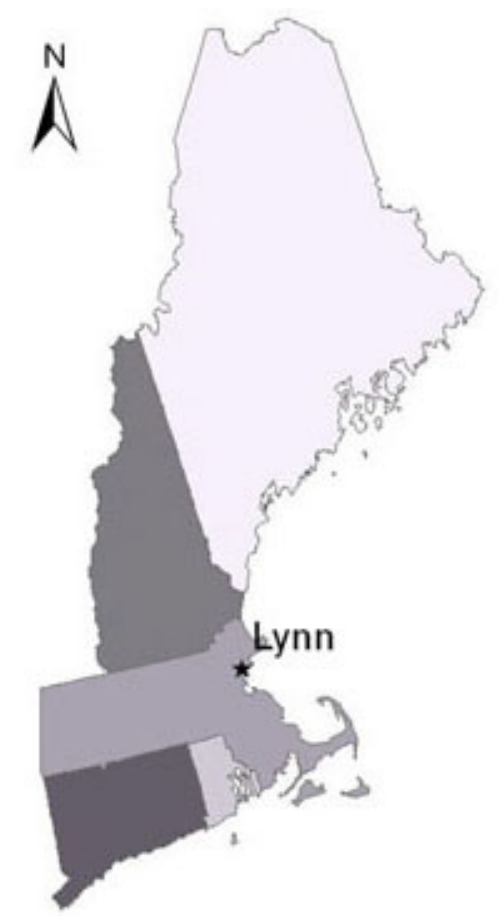

baseline level of participation using only those meeting dates that reported 20 or more attendees to prevent sparsely attended meeting dates from skewing the results. This process excluded 16 meeting dates out of $70(23 \%)$. We defined meeting dates with abnormally high attendance as those that had a participation level greater than 1.5 standard deviations away from the average attendance level. For these meeting dates, we collected and reviewed the posted agendas, motion minutes, and meeting minutes for particular policy implications and/or stakeholder involvement (accessed at http://www.n efmc.org). We used all meeting dates and their attendees for the distance analysis, as this analysis focused on overall participation.

\section{Industry representation}

To evaluate whether the observed participation was representative of the larger industry, we collected landings and permit data for the same time period. Using the methods of Syrjala (1996), we compared the spatial distributions of each of these data sets, attendees, landings, and permits, against the others to determine any significant $(\alpha=0.05$ and 0.01$)$ differences. The method uses the ordered calculation of distances of standardized locations to arbitrary origins and compares these differences between the two data sets. To evaluate potential differences in the geographic area considered, we used three different regions: New England (Maine to Connecticut); New England down to the Washington, D.C. latitude; and New England and the coastal mid-Atlantic (Maine to North Carolina).

\section{RESULTS}

\section{NEFMC meetings}

The mean center for the meeting locations from 2003 to 2006 was located in the county subdivision of Lynn, Massachusetts, in northeastern Massachusetts (Fig. 1). A linear regression of the natural log of the number of attendants and distance traveled was 
Fig. 2. Linear regression of the frequency of attendee distances traveled $(p<0.001)$.

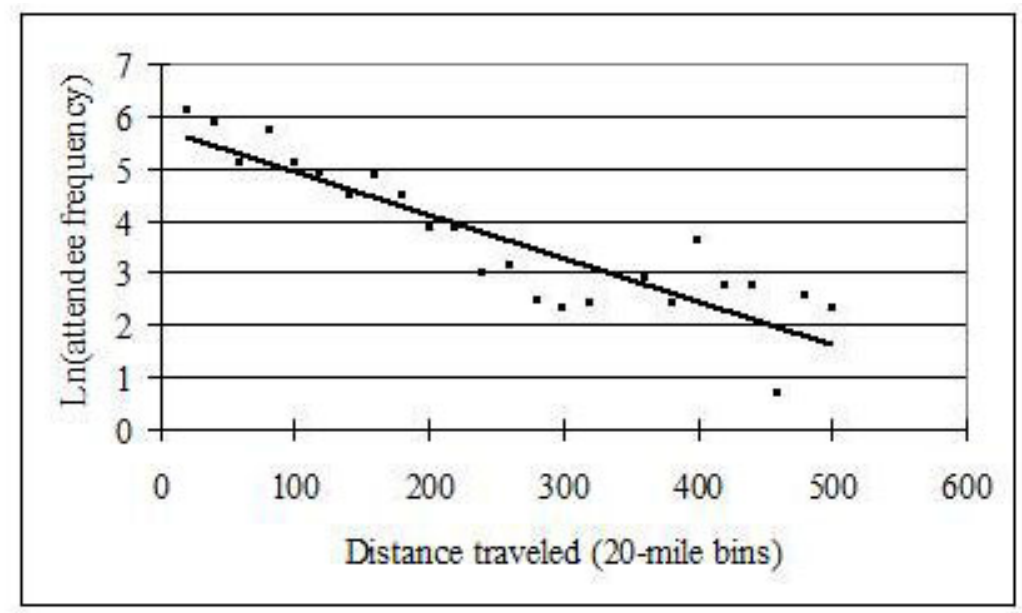

significant $\left(R^{2}=0.80, p<1 \times 10^{-8}\right.$, Fig. 2). An analysis of variance indicated a significant difference among the travel distances of the three fisheries, groundfish, scallop, and herring ( $p<$ 0.001). After the Bonferroni correction, this significant difference remained between the individual fisheries $(p<0.001)$. Histograms of distance traveled by the separate fisheries highlight the different distance distributions (Figs. 3-5).

\section{The focus fisheries}

A total of 12 meetings showed attendance levels higher than 1.5 standard deviations. When correlated back to the meeting agendas and minutes, all of the significant meeting dates corresponded to finalization of new regulations and fishery specifications, along with planning for upcoming regulations. We present one significant meeting date from each of the focus fisheries (Table 1) and use these three cases as examples of the broader pattern seen of participants' involvement.

On 12 May 2004, the high number of groundfish industry members that attended the Council meeting in Providence, Rhode Island, led to an industry member request, as recorded in the minutes, that the meeting location be moved to allow the many individuals standing in the hallway to enter the room. The Council denied the request in the interest of time but did grant industry leaders time to speak to the Council regarding Framework Adjustment $40 \mathrm{~A}$.

Framework Adjustment 40A defined the new Category B-Days-At-Sea (DAS) program that had originally been a part of Amendment 13 , voted in 2003 , but had yet to be fully developed. The B-DAS program days represented part of the compromise for reducing fishing days. This program was originally part of an industry proposal, as noted in the meeting minutes, and represented opportunities to regain lost income. Participants influenced the terms of the program, offering solutions to resolving issues regarding access, bycatch levels, and allotted DAS. Specifically, a suggestion from an industry representative to change the allocation of the $\mathrm{B}$ DAS over time was incorporated and passed.

An important meeting date for the herring fishery was 28 September 2006, when the 2007-2009 fishery specifications were set. The meeting minutes indicated a divide within the room, mainly between herring fishers on one side and conservation groups and tuna fishers on the other side. The sticking point regarded the allocation of quota between the inshore and offshore areas. Herring fishers advocated for maintaining the higher quotas in the inshore area, whereas 
Fig. 3. Distribution of groundfish attendee distances.

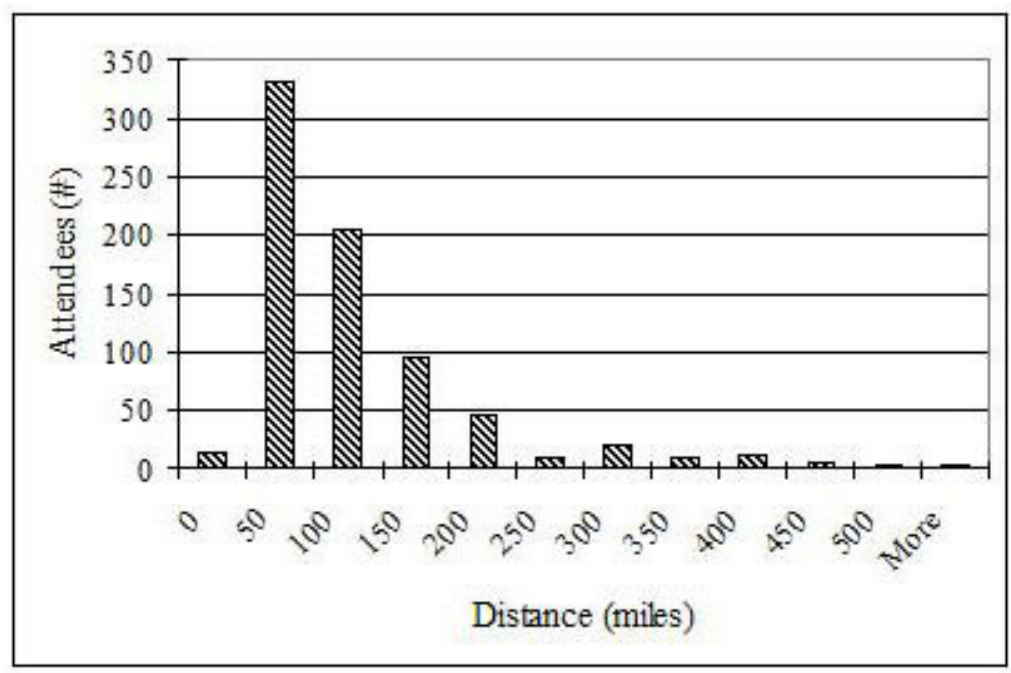

conservation groups and tuna fishers (who depend on herring schools to attract tuna) advocated for reduced quotas inshore. The debate lasted for nearly $2 \mathrm{~h}$ until an industry representative and member of the Herring Advisory Panel offered a compromise, saying that the Panel had supported a higher quota but would support a compromised decrease. A Council member incorporated this compromise into an amendment, which carried unanimously and with many members agreeing that this compromise was the best overall option.

Finally, the 24 February 2004 meeting held the final approval of and amendments to Framework 16/39, a joint framework to bring the scallop industry closures and bycatch quotas in line with the groundfish FMP. The industry's comments were instrumental in adjusting the cod bycatch limit in special access areas. Industry members acknowledged the dire state of the cod fishery and the need for caution when setting bycatch limits. However, the proposed zero-catch, they said, would risk a permit on the basis of one fish. They also argued that the cod are not targeted, but any that were caught would be regulatory discards under this plan and assumed dead. Stakeholders lobbied for retaining a small amount of cod bycatch for personal use. These arguments convinced the Council to incorporate this rule within the regulations, allowing the bycatch to be kept for personal use without compromising the vessel's permit. Furthermore, the Council incorporated the industry's recommendations for contingency measures should the regulations' implementation be delayed. These alterations reflected the Council's integration of the industry's input into regulations.

\section{Industry representation}

Overall the distributions of the landings and permits were non-significant from each other and the attendee distributions for all three fisheries. The only difference significant at the $95 \%$ confidence level was between permits and landings for the Washington, D.C. geographic distribution for the scallop industry (Fig. 6). Scallop attendee and landings distributions showed significant differences at the $90 \%$ confidence level for both the Washington, D.C. and North Carolina geographic extents. The permits and attendee distributions showed a significant difference at the $90 \%$ confidence level for the North Carolina geographic extent. No other significant differences were present. 
Fig. 4. Distribution of herring attendee distances.

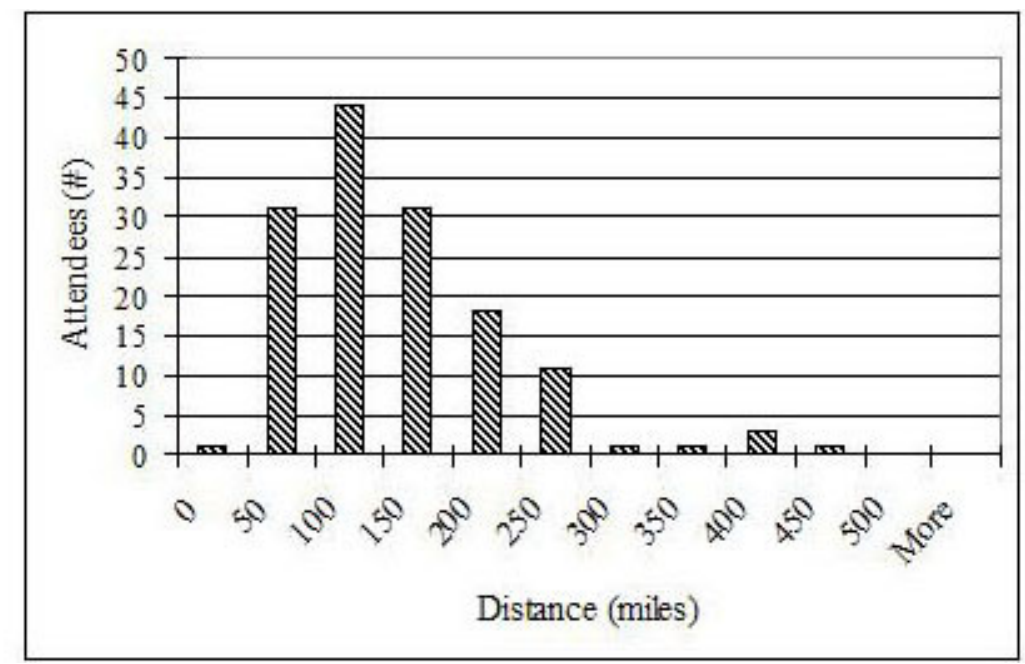

\section{DISCUSSION}

This study evaluated participation levels at the NEFMC general council meetings from 2003 to 2006. It assessed potential differences in representation between the focus fisheries and the observed representation. The data from this study support the previously shown trend that attendees who are geographically closer to meetings have a higher level of attendance (Osborne et al. 2000). The linear regression of distance traveled vs. attendee origin showed a highly significant and inverse relationship, supporting the geographic trend observed by Osborne et al. (2000) and Turner and Weninger (2005). The proximity of the meeting place to the major industry fishing ports could help explain some of the very high levels of attendance of nearby attendees. New Bedford, Massachusetts, which is less than $100 \mathrm{~km}$ away from the mean center of Lynn, Massachusetts, is one of the largest scallop ports in both the mid-Atlantic and the Northeast (Ocean Studies Board 2002). Many groundfishers are located around the port of New Bedford and also Gloucester, Massachusetts, which is within $50 \mathrm{~km}$ of Lynn. A large portion of herring fishers are also located around Gloucester, with the second largest port at Portland, Maine. These main locations of participants can help to explain the high attendance levels of nearby attendees but do not explain the significantly different distributions of the attendee distances for the three fisheries.

The financial success of the respective industries may help to explain the further-distant attendees (Osborne et al. 2000). The scallop industry is by far the most profitable of the three industries, having an ex-vessel value in 2006 of over \$325 million (NMFS 2007). Over the study period, this industry, through the Fisheries Survival Fund that represents most of the limited-access scallop vessels (D. Frulla and S. Gehan, personal communication, 13 August 2004), hired three different law firms to represent its interests at the NEFMC meetings. These law firms are located around Washington, D.C., accounting for the attendees coming from 700-800 $\mathrm{km}$. The herring industry, the next most profitable with a 2006 catch worth just under $\$ 240$ million (NMFS 2007), similarly hired these same law firms, although not as consistently, and thus the numbers of distant attendees in this range are slightly lower. Finally, the groundfish industry has been the least profitable, having a 2006 catch worth under $\$ 115$ million (NMFS 2007). Most of the attendees for this industry came from within $150 \mathrm{~km}$, with the levels of attendance dropping off beyond $225 \mathrm{~km}$. These travel distances may reflect not only the location of the fleet, as seen in the nearby attendees, but also the monetary aspects, as farther travel distances 
Fig. 5. Distribution of scallop attendee distances.

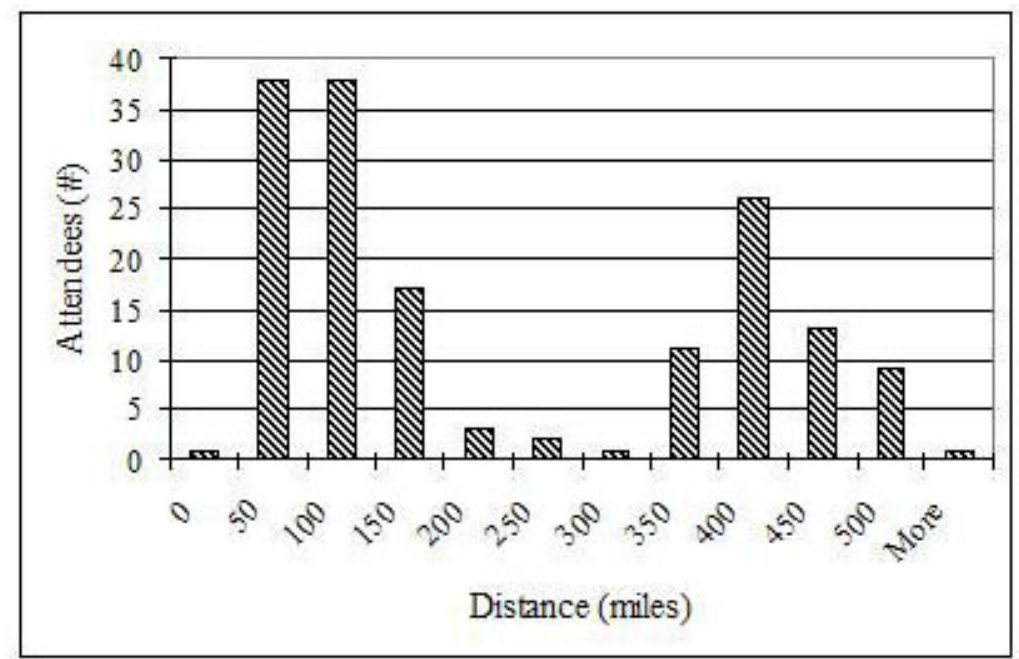

incur higher costs. Consistently further travel distances were more prevalent in the more profitable industries (scallop and herring). From the relative percentages of distances traveled by fishery attendees (Fig. 7), it is clear that nearby participants dominate the groundfish industry's attendance, possibly due to the factors listed above. Ground fishermen from along the Maine coast have voiced concerns regarding the costs of traveling to these distant meetings (J. Wilson, personal communication, 15 September 2006), reflecting this observed discrepancy in attendee travel distances.

Attempts have been made by the NEFMC to encourage and further increase participation by attendees. The following statement, written in boldfaced text, was distributed as part of the meeting agenda for the 15 April 2003 meeting:

Fishermen and members of the public are strongly encouraged to closely track the development of Amendment 13 to the Groundfish FMP. It will be especially important to attend Groundfish Committee meetings, as well as Council meetings, between now and July. The range of alternatives available for consideration in the amendment will be finalized during this period.
These agendas are posted at least $2 \mathrm{wk}$ before the meeting. Even with such an insistent message, the attendance for this meeting showed only slightly higher attendance levels, as defined in this study. The meeting, held in Danvers, Massachusetts, was less than $32 \mathrm{~km}$ from the mean center of Lynn, Massachusetts and was likely not a factor in the attendance level. Although meetings during the planning process of regulation may be less attended, due to multiple logistical reasons, the industries tended to respond to final decision council meetings. Most of the smeeting dates with significant attendance corresponded to some sort of final policy decision for that corresponding industry, reflecting Noll (1999) and Olson's (1965) observations that those groups most influenced by policy decisions are likely to participate. In these instances, those groups who would be affected by the decisive policy attended and lent their presence to the meeting's atmosphere. In each of our three examples, industry involvement specifically translated into decisions on policy that reflected the influence of their presence, as noted in the meeting minutes. In addition to these three dates, the meeting minutes for all meeting dates with significant attendance included comments from the Council members that indicated that the presence and arguments of the voluntary attendees persuaded their views and, more importantly, their votes on policy. These meeting minutes provide a key resource that 
Table 1. Examples of highly attended meetings. One meeting is listed for each focus fishery. Level of participation indicates the percentage of the industry's attendees compared with the total attendees present at the meeting.

Meeting Date Interest Fishery Level of Participation (\%) Policy action

\begin{tabular}{|c|c|c|c|}
\hline 24-Feb-04 & Scallop & 26.7 & $\begin{array}{l}\text { Joint Framework } 16 / 39 \text { for Scallop and } \\
\text { Multispecies Fishery Management Plans, } \\
\text { bringing closure areas in Scallop FMP in line } \\
\text { with closures of Multispecies FMP }\end{array}$ \\
\hline 12-Мау-04 & Groundfish & 68.1 & $\begin{array}{l}\text { Finalization of Framework Adjustment 40A to } \\
\text { Multispecies Fishery Management Plan: B } \\
\text { Days-at-Sea implementation }\end{array}$ \\
\hline
\end{tabular}

28-Sep-06 Herring $\quad 39.1 \quad$ Finalization of 2007-2009 specifications for herring allocations between inshore and offshore areas

attendance influences policy outcomes, supporting the previous observations that non-voting attendees can affect voted decisions (Bulkley et al. 2001).

The landings and permit data incorporate the larger industry, which the sign-in sheets cannot. Within the Washington, D.C. geographic extent, the comparison between permits and landings showed a significant difference in distribution that disappeared within both the larger and smaller geographic extents. This difference was likely due to the wider dispersal of permits in this area and along the New Jersey coast, with a large majority of the landings occurring only in Cape May and Barnegat Light, New Jersey, and New Bedford, Connecticut. This difference evened out once the Virginia and North Carolina permit holders and landings were included, displaying a more similar distribution. The high presence and influence of the scallop industry's legal counsel from Washington, D.C. were highlighted by this study, but these individuals could not be represented in either the landings or permit data. Although landings and permits would not capture these legal attendees, the design of the study highlights such discrepancies for further analysis, in this case indicating the legal presence.

The extreme drop-off of attendees from south of Washington, D.C. likely led to the differences seen between attendee and permit lists, and attendee and landings distributions for the North Carolina geographical extent, although this difference was only significant at the $90 \%$ confidence level. The difference between the landings and attendee distribution was more geographically prevalent, as this difference arose at the $90 \%$ confidence level within the Washington, D.C. geographic extent as well. This difference most likely reflected the landings that were present from Massachusetts down to North Carolina with far fewer attendeehailing points south of New England. Although the landings may have been more spread along the coasts than either the attendees or the permits, especially towards the mid-Atlantic region, the concentration of attendees, permits, and landings in New Bedford, Connecticut shaped these data sets and their similarities.

\section{CONCLUSION}

This study looked specifically at distance to the meeting location as a proxy for travel costs, along with interest of the attendees and possible effects on policy decisions and the representativeness of the attendance. Our results concurred with those projected in models in the literature (Turner and Weninger 2005) and suggested a possible association between travel distance (as a proxy for 
Fig. 6. Distributions of randomization for comparison of scallop distributions of permits and landings for the Washington, D.C. region. Solid line: Psi statistic; Dotted lines: 90\% CI; Dashed lines: 95\% CI.

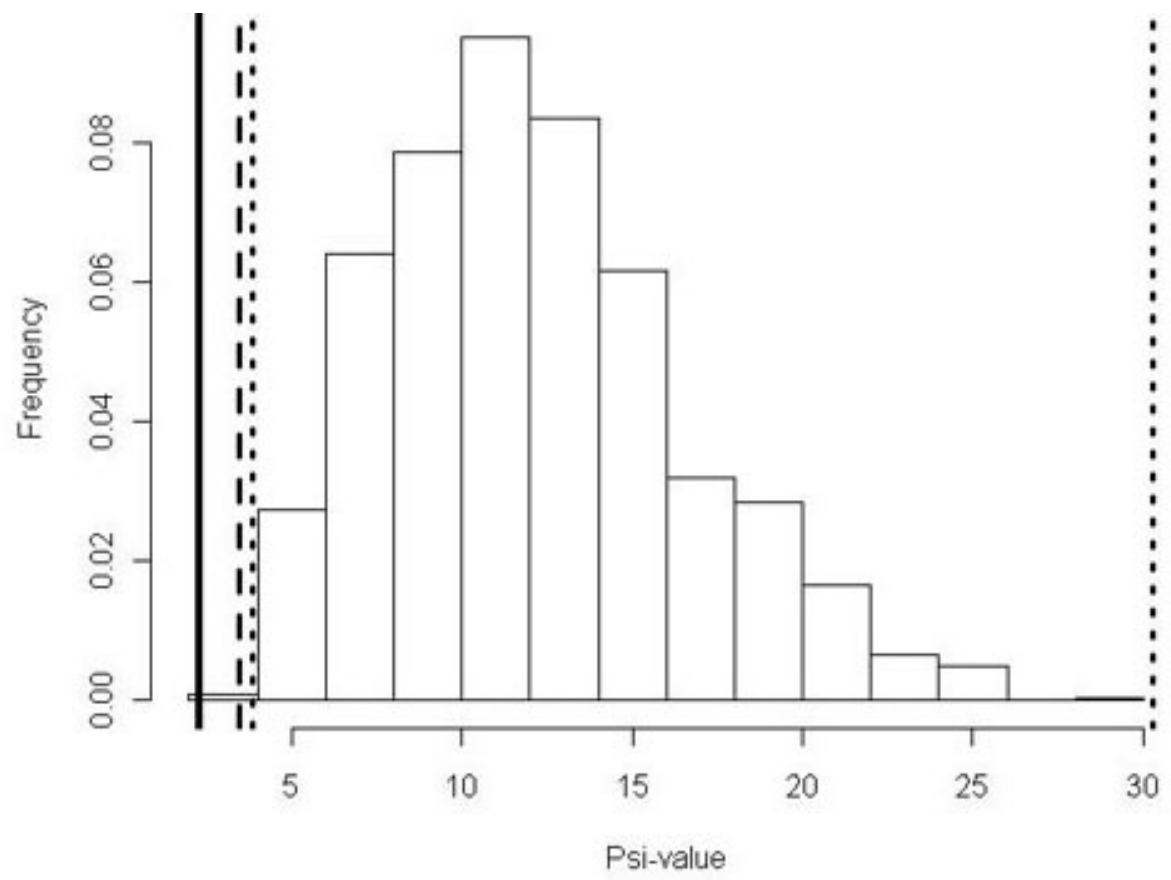

costs) and the likelihood of participation. The results from the interest analysis indicated that presence can be influential as well, seen through the incorporation of attendees' comments and views into the Council discussion and, sometimes, regulations. These results coincided with the research by Becker $(1983,1985)$ and Osborne et al. (2000) that suggested that fishermen and representative groups can be highly susceptible to the costs of voluntary participation. Finally, the distribution data highlighted some key representatives within the scallop industry, although on the whole indicating that the attendees present are not significantly different from the larger industry distribution.

Coupling these results with our distance analysis and representation analysis provides two potentially conflicting views. The distance analysis indicated that the participant make-up favors those individuals closer to the meeting location, possibly due to the travel costs incurred. However, the representation analysis indicated that overall few significant differences existed among the attendees and the industry's distribution, both in terms of permitted vessels and actual landings.

These results potentially reflect the centralization of the fisheries. This centralization can be due to more optimal habitats in certain areas, creating more-distant minorities in the fisheries. Additionally, this centralization can be from previous policy changes and influence that occurred before the beginning of our study. Our analysis occurred after earlier significant legislation that likely contributed to the fisheries' current distributions, possibly favoring those individuals within this geographic extent. Thus, our distance analysis would reveal a statistically significant relationship between attendee frequency and distance traveled while lacking any significant spatial differences in industry distribution from meeting attendance.

Considering the prior regulatory history in the previous decade, this explanatory theory is possible. The scallop fleet gained a limited-access control in 
Fig. 7. Industry attendee distances for groundfish, scallop, and herring industries. Data pooled to show the varying amounts across the distances.

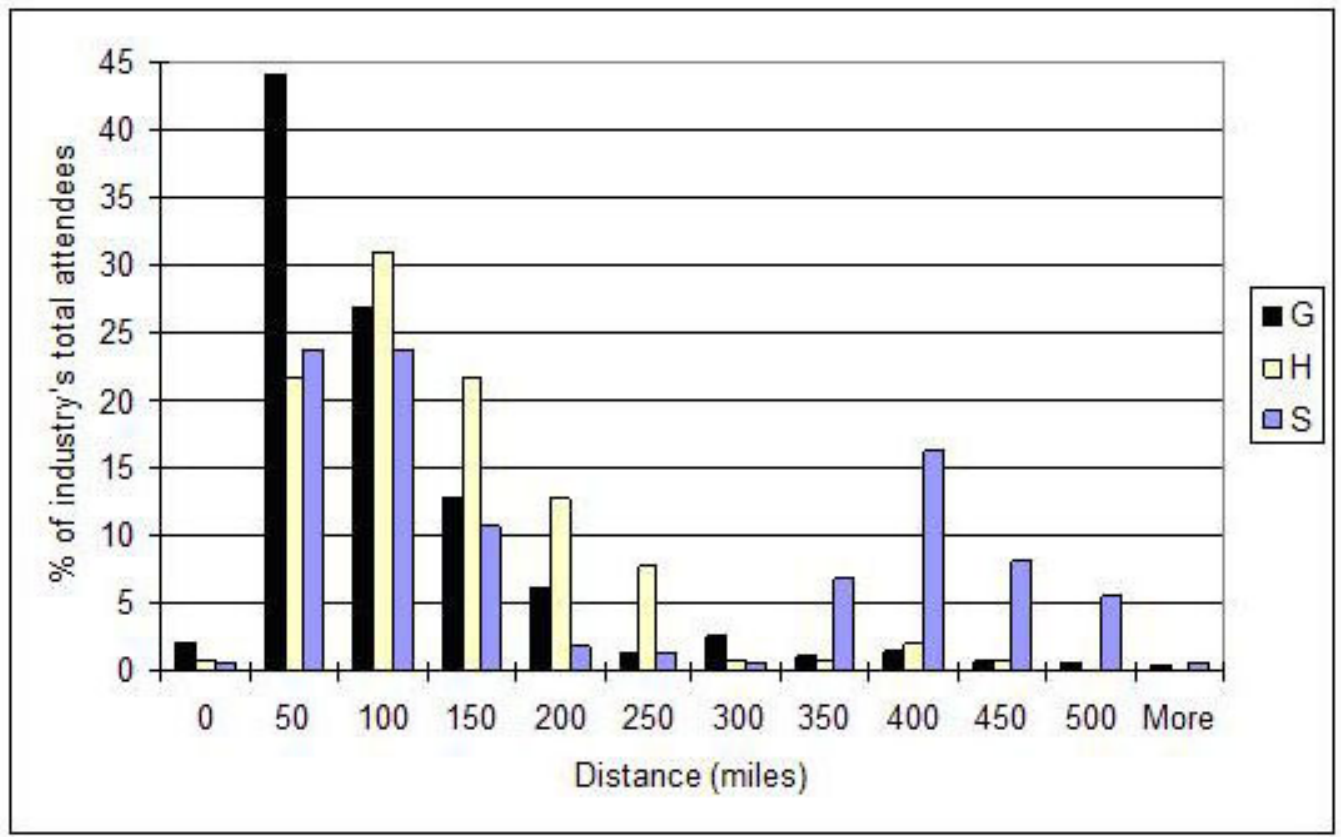

1994. At the same time, the groundfish closures on Georges Bank were implemented. These closures prohibited access to the scallop fleet to some of the most profitable grounds. The limited-access scallop industry regained access to these areas in 1999 and has become the most profitable industry in both the Northeast and mid-Atlantic (NMFS 2007). Edwards (2002) argued that this access came as a result of the scallop industry's voluntary participation and lobbying at council meetings. This potential success could have resulted in a positive feedback of attendance, influence, and results. In 2000, the herring FMP was developed to manage what was considered an under-utilized resource (NEFMC 1999). The study began in 2003 when Amendment 13 to the groundfish FMP, which restructured the permits and fishing rights, was passed. At the beginning of the study period, only those individuals with A-DAS could legally fish. The formation of the B-DAS programs (FA40A) occurred within the study period and provided a good example of increased participation and industry involvement (Table 1). However, these previous regulations may have shaped the fishery into a very different appearance than in the mid-1990s, not considering the initial federal fisheries management implementation in the 1970s. These events can only be alluded to, in terms of their effects on this research, as the same analyses have not been applied to those periods.

The emphasis of the Magnuson-Stevens Act on public participation has established the requirement for seeking public comment; however, the location of meetings and the lack of other options for involvement, such as teleconferencing, move the make-up of the participant pool toward individuals geographically closer or more financially able to attend. There has been a recent push to such options as phone- and teleconferencing within the NEFMC, but only for committee meetings currently. The North Pacific Fishery Management Council (NPFMC), which regulates federal waters off the shores of Alaska and incorporates Washington interests, has regularly used teleconferencing for both general council and committee meetings, providing local sites for the public (Department of Commerce, National Oceanographic and Atmospheric Administration, and North Pacific Fishery Management Council 2008, 2009). The increased use of such remote methods of participation, 
involving local community and academic sources of technology, could facilitate the involvement of more distant and less financially able groups.

These geographical biases are potentially magnified by the ecological distribution of the resource. The presence of a homogeneous resource would not involve any geographical issues in participation, as stakeholders would receive similar benefits and disadvantages of policy throughout the management's range. However, if stocks are not randomly distributed but rather portray a more metapopulationlike distribution, the lack of a broader range of stakeholder input coupled with the homogeneous management practices can have a much different outcome. The question becomes what are the outcomes should either assumption, homogeneous or clustered, be wrong. If indeed there is a single stock but management mistakenly assumes a metapopulation with local structure, extra time and effort would have been unnecessarily spent to include a broader range of input. Although the time spent may have been unnecessary from a biological viewpoint, the extra effort could be beneficial from a social standpoint. If the population stocks are clustered in a metapopulation structure but are assumed to be a single undifferentiated population, policies implemented for the larger region without considering a broader range of input may negatively impact the existence of local sub-populations (Wilson 2006). Geographically biased input on regulations that affect a larger, heterogeneous stock may not have the assumed homogeneous results across the region. Work on Atlantic cod has yielded conclusions of a metapopulation structure, with subpopulations of spawning groups spread or previously spread throughout the three managed areas, with current declines in localized areas (Sinclair 1988, Ruzzante et al. 1998, Ames 2004). The difference in the outcome should be a weighed factor in the decision-making process.

This conflict between stock structure assumptions and management has produced a wide body of literature on the issues of scale, both in the operational or geographical sense of the term (Hartje 2002) and its political sense of hierarchical management (Swyngedouw 2004, Silver 2008). This issue is so ubiquitous in natural resources management, and aquatic resources specifically, due to the fact that resource boundaries rarely coincide with institutional or government boundaries (Folke et al. 1998). A popular argument recently has been to decrease the scale of governance, managing as close to the community scale of the resource as possible (Subramanian et al. 1997), for its advantages in lowering transaction costs of management and increasing familiarity with the local resource. However, the presence of crossscale linkages, both politically and ecologically, prevent any single-scale approach from being completely sufficient (Berkes 2006, Cash et al. 2006). These factors complicate the NEFMC's and any other management body's ability to successfully incorporate social and ecological feedback into the management structure. The advantages, however, as noted by Cudney-Bueno and Basurto (2009), of incorporating these feedbacks provide for successful and sustainable fisheries. Thus, although management scale is a human construct, influenced by political boundaries and processes and scientific conceptions (Swyngedouw 2004, Brown and Purcell 2005), the maintenance of social and ecological resilience requires that such scaled feedback be recognized and incorporated into adaptive management regimes (Tompkins and Adger 2004, Hughes et al. 2005).

Future research, including further defining participation costs and interests and interviewing Council members and participants, would help to either explain these conclusions or redirect the research. These efforts would be conducted in hopes of further improving the effectiveness of the regional council system in regulating the nation's fisheries.

Responses to this article can be read online at:

http://www.ecologyandsociety.org/voll5/iss3/art2/responses/

\section{Acknowledgments:}

We would like to thank the University of Maine Provost Fellowship, the Kendall Foundation, the Maine Sea Grant, and the Saginaw Field and Stream Club for supporting this research. We would also like to thank Teresa Johnson and the reviewers for their comments and those who assisted in making the sign-in sheets and minutes available. 


\section{LITERATURE CITED}

Allen, G. 1991. Rhode Island flounder (Part 1). The Fisherman August 8:12-13.

Ames, E. 2004. Atlantic cod stock structure in the Gulf of Maine. Fisheries 29:10-28.

Becker, G. 1983. A theory of competition among pressure groups of political influence. The Quarterly Journal of Economics 98:371-400.

Becker, G. 1985. Public policies, pressure groups, and dead weight costs. Journal of Public Economics 28:329-347.

Berkes, F. 2006. From community-based resource management to complex systems: the scale issue and marine commons. Ecology and Society 11(1): 45 [online]. URL: http://www.ecologyandsociety.org/ vol11/iss 1/art45/.

Brown, C., and M. Purcell. 2005. There's nothing inherent about scale: political ecology, the local trap, and the politics of development in the Brazilian Amazon. Geoforum 36:607-624.

Bulkley, G., G. Myles, and B. Pearson. 2001. On the membership of decision-making committees. Public Choice 106:1-22.

Cash, D., W. Adger, F. Berkes, P. Garden, L. Lebel, P. Olsson, L. Pritchard, and O. Young. 2006. Scale and cross-scale dynamics: governance and information in a multilevel world. Ecology and Society 11(2): 8 [online]. URL: http://www.ecology andsociety.org/vol11/iss2/art8/.

Conservation Law Foundation v Evans. 2001. DDC, 209 F. Supp. 2d 1.

Cudney-Bueno, R., and X. Basurto. 2009. Lack of cross-scale linkages reduces robustness of community-based fisheries management. PLos ONE 4:e6253.

Department of Commerce, National Oceanographic and Atmospheric Administration, and North Pacific Fishery Management Council. 2008. Notice of a public committee meeting. 73. Federal Register 250:79829.
Department of Commerce, National Oceanographic and Atmospheric Administration, and North Pacific Fishery Management Council. 2009. Notice of a public meeting by teleconference. 75 . Federal Register 10:2489.

Edwards, S. 2002. Rent-seeking and property rights formation in the US Atlantic sea scallop fishery. Marine Resource Economics 16:263-275.

Environmental Systems Research Institute (ESRI). 2007. ArcGIS 9.2. ESRI, Redlands, California, USA.

Fishery conservation. 2005. Subcommittee on Fisheries Conservation, Wildlife, and Oceans of the Committee on the House Resources, House, 109th Congress.

Folke, C., L. Pritchard, F. Berkes, J. Colding, and U, Svedin. 1998. The problem of fit between ecosystems and institutions. Human Dimensions Programme on Global Environmental Change, Bonn, Germany.

Hart, D., and P. Rago. 2006. Long-term dynamics of US Atlantic sea scallop Placopecten magellanicus populations. North American Journal of Fisheries Management 26:490-501.

Hartje, V. 2002. International dimensions of integrated water management. Pages 7-34 in I. AlBaz, V. Hartje, and W. Scheumann, editors. Cooperation on transboundary rivers. Nomos, BadenBaden, Germany.

Hughes, T., D. Bellwood, C. Folke, R. Steneck, and J. Wilson. 2005. New paradigms for supporting the resilience of marine eocsystems. Trends in Ecology and Evolution 20:380-386.

Magnuson-Stevens Fishery Conservation and Management Act. 1976. 16 USC 1801.

McCool, S., and K. Guthrie. 2001. Mapping the dimensions of successful public participation in messy natural resources management situations. Society and Natural Resources 14:309-323.

Merrell Katsouros, L. 2003. Constituents views on improving federal fisheries management, a synthesis report. National Oceanographic and 
Atmospheric Administration, Washington, D.C., USA.

New England Fishery Management Council (NEFMC). 1985. Fishery management plan environmental impact statement regulatory impact review and initial regulatory flexibility analysis for the Northeast multi-species fishery. NEFMC, Gloucester, Massachusetts, USA.

NEFMC. 1999. Final Atlantic herring fishery management plan incorporating the environmental impact statement and regulatory impact review (including the Regulatory flexibility analysis), Volume I. NEFMC, Saugus, Massachusetts, USA.

National Marine Fisheries Service (NMFS). 2007. Annual commercial landings statistics. (online) URL: http://www.st.nmfs.noaa.gov/st1/com mercial/landings/annual landings.html.

Noll, R. 1999. The economics and politics of slowdown in regulatory reform. AEI-Brookings Joint Center for Regulatory Studies, Washington, D.C., USA.

Ocean Studies Board. 2002. Habitat mapping and distribution of fishing effort. Pages 30-47 in Effects of trawling and dredging on seafloor habitat. National Academy Press, Washington, D.C., USA.

Olson, M. 1965. The logic of collective action. Harvard University Press, Cambridge, Massachusetts, USA.

Osborne, M., J. Rosenthal, and M. Turner. 2000. Meetings with costly participation. The American Economic Review 90:927-943.

Ruzzante, D., C. Taggart, S. Lang, and D. Cook. 2000. Mixed-stock analysis of Atlantic cod near the Gulf of St. Lawrence based on microsatellite DNA. Ecological Applications 10:1090-1109.

Silver, J. 2008. Weighing in on scale: synthesizing disciplinary approaches to scale in the context of building interdisciplinary resource management. Society and Natural Resources 21:10,921-10,929.

Sinclair, R. 1988. Democracy and participation in Athens. Cambridge University Press, Cambridge, UK.
Stigler, G. 1971. The economic theory of regulation. Bell Journal of Economics 2:3-21.

Subramanian, A., Jagannathan, N. and Meinzen-Dick, R. 1997. User organizations for sustainable water services. The World Bank, Washington, D.C., USA.

Swyngedouw, E. 2004. Scaled geographies: nature, place, and the politics of scale. Pages 129-153 in E. Sheppard and R. McMaster, editors. Scale and geographic inquiry. Blackwell, Oxford, UK.

Syrjala, S. 1996. A statistical test for a difference between the spatial distributions of two populations. Ecology 77:75-80.

Tompkins, E., and W. Adger. 2004. Does adaptive management of natural resources enhance resilience to climate change? Ecology and Society 9(2): 10. [online] URL: http://www.ecologyandsociety.org/vol9/ iss $2 / \operatorname{art} 10 /$.

Turner, M., and Q. Weninger. 2005. Meetings with costly participation: an empirical analysis. Review of Economic Studies 72:247-268.

Wilson, J. 2006. Matching social and ecological systems in complex ocean fisheries. Ecology and Society 11(1): 9. [online] URL: http://www.ecology andsociety.org/vol11/iss 1/art9/. 